\title{
The Contribution of Albanian Northern Authors to Translation Mastery: Ndre Mjeda, Ndoc Nikaj and Qemal Draçini
}

\author{
PhD. Vjollca Osja \\ University of Tirana, Faculty of History-Philology, Department of Literature \\ Email: vjollcaosja@yahoo.com
}

\section{Doi:10.5901/mjss.2014.v5n10p657}

\begin{abstract}
In the 1930's, translation issues in Albanian literature, emerging somewhat recently as an aesthetic awareness, resluted essentially problematic. Among the values recognized to translation, three were considered of primary importance: 1 . Language processing and development to the extent of making it usable to overcome the test of translating everything. (The translator Vedat Kokona claimed a few years ago that Albanian language managed to bring into the Albanian culture masterpieces of antiquity, thus this test was perfectly passed). 2. The necessity to have artistic models and references by writer who already had a clear vision about the relation between the patriotic and the literary in a literary work. 3. The necessity of creating a paradigm of cultivated readers with a refined literary taste. In the 1930's, it seemed that it was already forme a group of artists, who were influenced or not by the culture of the countries where they received their university education, considered the literary product, first and foremost as an aesthetic consciousness while the necessity of translations was considered as indespensable. Along with translations in literary forms (newspapers) or books, literary theories about specifics that art of translation must have ad a remarkable development. Treatises on the art of translation were compiled in the prefaces of the translated books, or were included in the form of critical discussions in their forewords.
\end{abstract}

Keywords: literary translation,Albanian literature, artistic models, translator, writer.

Since the time when Livius Andronicus, dramatist and epic poet, made accessible for Romans (240 BC) to read for the first time Homer's Odyssey into Latin verse, the literary art world started a very ardous journey of inter-communication process which is frequently manipulated: that of translation. In the realm of art emerged a mastery which often journeyd through many prejudices of definitions of negative connotations (Let's recall the Italian stigmatizing proverb "Traduttore, traditore"), in order to entrust it to the mission it emerged in this field: "To make the translation of the spirit that a capable author has embodied in his work", which implies not only transferring the originating text of the language, but likewise the specific spirit that characterizes the uniqueness of a specific author and a certain country into another language.

This issue, which fueled since the outset, the silent duel among theories of possibility an the impossible mision of the literary translation from one language into another language, expanded in space and time, depending on developments in literary translation and culture. Theories of Cicero (1st century) could perhaps be mentioned to mark the begginnings of this duel, when he wrote about the translation of "Discorsi " of Demosthenes and Eskin, a translation that embodied the dilemma between two translation variants, that of the loyalty to the originating language versus the free literary translation; he appreciated the second, having the writer's conviction that regarding the text, the reader should be provided with the weight of its words, rather than their precise number.

Translation issues in Albanian literature, emerging somewhat recently as an aesthetic awareness, resluted essentially problematic. Among the values recognized to translation, three were considered of primary importance:

1. Language processing and development to the extent of making it usable to overcome the test of translating everything. (The translator Vedat Kokona claimed a few years ago that Albanian language managed to bring into the Albanian culture masterpieces of antiquity, thus this test was perfectly passed)

2. The necessity to have artistic models and references by writer who already had a clear vision about the relation between the patriotic and the literary in a literary work.

3. The necessity of creating a paradigm of cultivated readers with a refined literary taste.

In the 1930's, it seemed that it was already forme a group of artists, who were influenced or not by the culture of the countries where they received their university education, considered the literary product, first and foremost as an aesthetic consciousness while the necessity of translations was considered as indespensable. Along with translations in literary forms (newspapers) or books, literary theories about specifics that art of translation must have (we are refering to is as "art" since translation is art and that's beyond doubt) had a remarkable development. Treatises on the art of 
translation were compiled in the prefaces of the translated books, or were included in the form of critical discussions in their forewords.

Nineteen centuries after Cicero, Ndre Mjeda, another classic of the original literary works, considered as important to elaborate on the values of literary translations in a country where their function, in the rare cases when it had flourished (especially the Philo-Biblical literature) it had been utilitarian rather than of artistic nature. Now everything had to be established based on the level where transposition came from literary experience and not from the translation of each word something that unweaves the poetics of the literal text. Therefore, not surprisingly, the foregoing translator, Ndre Mjeda, the poet of the musical language, was the unique translator of the Goethe's poem "King of Thule". In an effort to align the values of the translation made by Ernest Koliqi in his translation entitled "Great Poets of Italy", Mjeda established the rules, almost alphabetical rules of a translation treaty.

By ignoring that group of translators and translations, which were unfortunately among many that "do not have any value besides simply violating our language" something which transforms them "from translators into ill-transmitters", Mjeda emphasized the indespensable condition of giving a positive response to the question if it was possible, generally speaking, for a literary work to be translated into another language. This condition according to Mjeda is related to translator's creative intuition: to the level he manages to capture the ontology of the original work, its spiritual and aesthetic uniqueness, so that these qualities are not disfigured and lost during the translation process, but come naturally to the readers of the host language and reproduce the same effect it had in the original language, which is the reason why it is usually said that it is not the author who is translated, but first of all, the spirit of his work in Albanian language. ("You can try to translate a poem for many days and nights and again, nothing that satisfies you appears. This can't happen unless you have the talent of poetry, which is a mystery, a secret, a thing that obeys no rules, no laws")

Being ostentatious on words and a master of the writing original leterary works, enabled Mjeda to apply in his translations the free translation theory, namely, recreation of the translated work (such is the case of the translated poetry of Capparozzo The Fratricide, The Dead of Sir John Moore translated by Wolf), this theory that brought him closer to the controversial principle of the Italian aesthetist Benedetto Kroce, that translation in order to become genuinely the same as the original, is a work re-created by the translator, thus a recreation of the original work, while retaining its spirit.

Based on this theory, the deduction that even if technically translation is a binary process, a process that requires knowing both languages, the receiving and transmitting language, this fact should not be considered as absolute, one should not forget that even if " we suppose there is a language that can fully offer the word equivalent for every word, the equivalent phrase for each phrase having precisely the same meaning, the same power that the original work has, yet remains something that can't be shown, and this is the key to the mastery, transfering the spirit that the author has given to his work, the spirit that brings to life a literary work in the same way as bringing to life a lifeless body" Hence, Mjeda establishes the second necessary condition, "the translator should have the same spirit and be in the same level with the author who wrote the work". (Even here, one notes that he agrees with the assertion of B. Kroce "translations can be made by writers who have the same talent with the author that he translates").

Having reached the level of the system, these two conditions seem to make difficult the possibility of translating the work, but do not make it impossible. It is of no surprise, asserts Mjeda, that there are very few good translators. In order to come closer to the model translator (or better say according Mjeda, it is neccessary that the translator's feelings should "be ine the same line with" the author. The reference he makes to two great Italian masters of translation from the GreekLatin antiquitiy literature provide two models:

The first model, (that appreciated by Mjeda) is the model of Vincenzo Monti, who translated "lliad" without genuinely knowing the Greek grammar, but by knowing very well the foreign translations and remarks of the grammar scholars and above all, being a poet himself, "he felt indeed the poetic beauties of lliad" and "...managed to go further than his contemporaries with his translation." The second model is that of Anabal Caro, who although managed to create a valuable work in the aspect of the metrics and the poetic vocabulary, failed to bring into another language the spirit of Virgil, since "in translation, vaguely portrays the face of the Roman poet".

It seems that based in these arguments, we can specify the fundemental rule of Mjeda's treaty, according to which it is not good enough to know the foreign language and your language, but one must manage to grab the special spirit of the original author given to his own work, so that work is not "disfigured" and translation, if we refer to the concept of Umberto Eco on translation of texts with aesthetic value, causes the same effect intended to be evoked by the original.

The presence or atmosphere of the serious concern about translations in the 1930s, is noted even in the article "Literary translations in our language" of Ndoc Nikaj. If we observe how the author tries to approach the problem, we note that he applied the strict steps of the translation theorist, while he practically knows very well the value of the translation and its situation in Albanian literature. By submitting evidence of questionable literary translation formats, he expressed his concern about two dangerous trends of part-time translators of literature (amateur translators), who frequently, not 
having at all any relation to the act of composing the work:

1. They make a translation from French or English that is repeated by Albanian words: similiar phrases and expressions while the spirit remains solely to the work of the original language while in the Albanian language these works sound completely foreign.

2. They dare to translate "not using the original, but using another language", thus forgetting that "the literary works, however well-translated, lose more when translated from the original language into another language" therefore it is not hard to imagine what remains to be translated from the translation of a translated text. Furthermore, we can imagine how critical this issue is, if we consider what Robert Frost noted that poetry is what is lost in translation.

These two trends have no other influence beside discouraging the new readers, on the expense of whom the amateur translators practise their school exercises. Recognizing himself as one of those who accept that translation process is difficult and delicate, Nikaj reinforced Mjeda's statement that rather than a technical job, literary translation is an act of recreation. It "requires a certain inclination, passion, talent, a refined taste, an exquisite sensibility." Regarding the importance of translation, Ndoc Nikaj affirmed the great value they have, especially in those countries where the language is not yet fully formed. Artistic translation led to the expansion and lexical, semantic and syntactic processing of the language. References to linguistic histories of different countries prove this to us. Translation of Plutarch by Amyot, according to Nikaj, played an important role in the formation of French language, the same as Montaigne translations in English had a profound influence on Shakespeare. Likewise, analogously, the translation into Albanian of the Holy Scriptures by Kostandin Kristoforidhi played a role in the development of the Albanian language. One can add also that translation plays a major role in shaping the language of literary speeches. This process helps the art in gaining its autonomy and codifies the language of drama, novel, poetry etc. We think that such a role was played by Fan Noli's translations in our language.

"Only by means of translation, literatures of different nations merge with one another and become a common artistic property of the civilized humankind." One question, which he considered as the key issue for writers, translators and critics, was related to the limit a iterary work could reach in the translation process Meanwhile, the introduction of the term "exact" made him have the dilemma between two alternatives: the translation "ad litteram" which means the literally translation or the recreation of the original work (based on the Croce's concept on the translator as a writer, while trying to maintain the spirit and overall structure of the literary work. Considering it as an inappropriate term for art and the most undefinable thing regarding translation, he rejected the first alternative, and accepted the second, while doubting the concept of the translator as a writer who has the same talent as the author being translated. According to Nikaj, this is not necessary, "even more it can also be harmful," because "when a translator is a great writer, he is influenced by his talent and can create a new work, which is quite different from the original" In this case how do retain the spirit of the original literary work? What about the poetics of the originating text?

If not a writer (original composer of literary works), the translator of novels must possess some qualities that define the talent of these kind translators-firstly, the sensitivity, imagination, literary technique of writing and the critical sense that assesses the author's thoughts and enables him to distinguish the most elaborated word connotations that the literary word of the original text may have. However, Nikaj was completely sure of the necessity of the translator who is a poet in case of translating lyrical poetry, since the reproduction of the images and of the musical harmony of language is of absolute importance.

In his paper "On a system of translation", the writer and translator Qemal Draçini, while considering translation as "the most important cultural indicator of a country" he emphasizes the mess of translations, a mess in which the concepts of value, taste and the literary work do not exist, except their opposites, which are a result of the so-called "pen industry". According to Qemal Draçini, the reasons of having this situation are two:

1. Lack of a supreme initiative of any private publishing house, to result in a coordinated and systematic work.

2. Lack of liteary maturity and social responsibility.

Therefore, having the desire to establish order and guide what needed to be guided, Draçini, considering the thesis of translations, wished to establish a system of conditioning thesis of "translations that are desirable to be made" and, secondly, "translations that are indespensable to be made". "We need to translate the masterpieces of all periods and all countries starting from the classic works of antiquity and ending with the most important contemporary literary works. But this great deal of work is disproportionate with our current capability. Thus, automatically, we tend to simplify what we must do by differentiating between "what is desirable to be translated and what is indespensable to be translated." Having to choose between the necessity and indespensability, he emphasised the second. He chose the second, not as the end of the problem but as solution to it, in order to be, at least consistent with the echoes of the European literary production, philosophical and scientific works. He mentioned among the works that "should definitely translate the literary and 
scientific masterpieces of the second part of the past century and the most important literary, philosophical, scientific, political works of our century."

Regarding the issue of the quality of translators, Mjeda and Nikaj emphasized the necessity of a translator equipped with the capability of meeting three equally important requirements:

1. Good knowledge of the originating language he translates.

2. Good knowledge of the language in which he translates.

3. Translator's possession of the literary experience.

According to Qemal Draçini, the first condition, "is a conditio sine qua non" because it is natural that without knowing the language of the original work and its entire features, its phraseology," starting the translation would be a bald initative, if not absurd". But the cardinal point of the problem, according to Draçini, lies in the second quality: knowing the nature of the Albanian language which in reality is ignored by the translator as well as by publishing house that requires a translation. "It goes without saying that a translation made in this way is not a translation at all. It can be e literally ordering of the words of a foreign text with Albanian words, but, not a translation in Albanian language" Therefore, what Draçini asserts, definately sounds convincing "one should remember that to translate means to do perhaps a more difficult job than composing an original literary work"

\section{References}

Mjedja, Ndre, Leka, v. IV, nr. 9, Shkodër, shtator1932, fq. 285

N.N (Pseudonimi i Ndoc Nikës), Illyria, v. I, nr. 38, Tiranë, 1936, fq.2

Draçini, Qemal revista Fryma, v. I, nr. 2, Shkodër 1944

Plasari, Aurel, revista Nëntori, nr. 12. V. 1987, fq. 122

The Cambridge Introduction to Robert Frost, Robert Faggen, Cambridge University, Press 2008.

Kokona, Vedad, Mbi përkthimin, Toena, Tiranë 2003.

Ecco ,Umberto Të thuash gati të njëjtën gjë, Dituria, Tiranë, 2006.

Croce Benedetto, Estetica come scienza dell' espressione e linguistika generale, sesta edizione riveduta, Bari, Laterza \& Figli, 1928. 